\title{
The etiology of the ECG "U" wave
}

\author{
Kenneth M Eyer* \\ 369 Old Sawmill Road, Sagle, Idaho 83860, USA
}

\section{Letter to the Editor}

When I was a Cardiology Fellow in the 1950's at the University of Washington, I was curious why the $\mathrm{U}$ wave had been observed for 100 years but had never been explained. Because it looked like a miniature $\mathrm{T}$ wave researchers had assumed it had to be late repolarization somewhere in the heart. But search as they may, they couldn't find it.

I looked at the large book "The U Wave" by Katz and found the most help on the first page. They are largest in the chest leads of young males and always follow the aortic second sound. I attached a phonocardiogram and ECG leads to myself and varied my stroke volume by going from a Val Salva to a Mueller maneuver and back. The ECG stayed the same except for the second heart sound and the $U$ wave which marched back and forth in lock step. The $U$ wave had to be caused by something mechanical that happened right after the closure of the aortic valve. Could it be the movement of ventricular relaxation?

I knew that moving the specimen or the recording electrode when recording from a heart in a saline bath can cause a deflection, so it followed that cardiac movement in early diastole might give rise to the
U wave. What followed were years of watching ECG's and the U waves to see if there was ever an exception to this rule.

Post extra-systolic pulsus alternans is a well-known sign of impaired left ventricular function. I reasoned that the ECG should also show $\mathrm{U}$ wave alternans and I watched for it. One night on the coronary care unit the resident showed me a rhythm strip on a patient and there it was. I took members of the house staff to the patient's bedside and we each put a finger on a pulse. A PVC came along and we each noticed transient pulsus alternans.

Later, six of my patients who had been in heart failure volunteered to be monitored in our Heart Center. Each one showed trancient Uwave and pulsus alternans after a PVC. I wrote it up for the American Heart Journal. Not long after that I had a very obese patient who was getting an ECG. I took the opportunity to put my finger on his V-4 electrode and moved it up and down in sync with his heart rate. When the electrode was moving away from the heart in early diastole it cancelled out the heart movement, and the $U$ wave vanished. When it was moving towards the heart instead, the $\mathrm{U}$ wave became twice the size. Here was the final proof that the ECG $U$ wave is indeed caused by ventricular movement. Case closed. The mystery was solved.
Copyright: (C2019 Eyer KM. This is an open-access article distributed under the terms of the Creative Commons Attribution License, which permits unrestricted use, distribution, and reproduction in any medium, provided the original author and source are credited.
${ }^{\star}$ Correspondence to: Kenneth M Eyer, 369 Old Sawmill Road, Sagle, Idaho 83860, USA, E-mail: sallyken1@frontier.com

Received: July 04, 2019; Accepted: July 08, 2019; Published: July 12, 2019 